\title{
Research
}

\section{Implications of comorbidity for primary care costs in the UK:}

\author{
a retrospective observational study
}

\begin{abstract}
\section{Background}

Comorbidity is increasingly common in primary care. The cost implications for patient care and budgetary management are unclear. Aim

To investigate whether caring for patients with specific disease combinations increases or decreases primary care costs compared with treating separate patients with one condition each

\section{Design}

Retrospective observational study using data on 86100 patients in the General Practice Research Database.

\section{Method}

Annual primary care cost was estimated for each patient including consultations, medication, and investigations. Patients with comorbidity were defined as those with a current diagnosis of more than one chronic condition in the Quality and Outcomes

Framework. Multiple regression modelling was used to identify, for three age groups, disease combinations that increase (cost-increasing) or decrease (cost-limiting) cost compared with treating each condition separately.

\section{Results}

Twenty per cent of patients had at least two chronic conditions. All conditions were found to be both cost-increasing and cost-limiting when co-occurring with other conditions except dementia, which is only cost-limiting. Depression is the most important costincreasing condition when co-occurring with a range of conditions. Hypertension is costlimiting, particularly when co-occurring with other cardiovascular conditions.
\end{abstract}

\section{Conclusion}

Three categories of comorbidity emerge, those that are: cost-increasing, mainly due to a combination of depression with physical comorbidity; cost-limiting because treatment for the conditions overlap; and cost-limiting for no apparent reason but possibly because of inadequate care. These results can contribute to efficient and effective management of chronic conditions in primary care.

\section{Keywords}

comorbidity; costs and cost analysis; delivery of health care; depression; family practice; resource allocation.

\section{INTRODUCTION}

The prevalence of patients with comorbidities $^{1}$ is increasing in most developed countries. Almost all major diseases are more common with increasing age, and as populations age the number of people with multiple problems is likely to increase. ${ }^{2}$ This could have an effect on healthcare resource use over and above that due to ageing alone if the cost of treating a patient with several conditions differs from the cost of treating separate patients with one condition each. There is some evidence that a patient with more than one condition has greater secondary care resource use than separate patients each with one condition. ${ }^{3,4}$ However, the evidence for primary care, where many patients with comorbidity are managed on a day-to-day basis, is weaker. In a small study using Irish data Glynn et a ${ }^{5}$ found some evidence of an overall increase in primary care costs associated with multimorbidity, however, this was not supported in a more extensive study. ${ }^{6}$ Other studies have focused on specific combinations of diseases. ${ }^{7-9}$

Greater understanding of comorbidity and its impact on the use of primary care has implications for both the clinical management of patients and health service planning and financing. Information about how different diseases interact in terms of resource use can offer guidance on case management, could improve the

SL Brilleman, BSc, research associate; S Purdy, MD, FRCGP, reader in primary health care; C Salisbury, MD, FRCGP, professor in primary health care; $\mathbf{S}$ Hollinghurst, $\mathrm{PhD}$, senior lecturer in health economics, Centre for Academic Primary Care, School of Social and Community Medicine, University of Bristol, Bristol. F Windmeijer, PhD, professor of econometrics, Department of Economics, University of Bristol, Bristol. H Gravelle, PhD, professor of economics, Centre for Health Economics, University of York, Heslington, York. efficiency of service provision, inform resource allocation to general practices so that patients' needs are better met, and may be important in creating financial incentives for better care when patients require the same intervention for more than one chronic condition.

This article examines the implications of a wide range of comorbidities on resource use in primary care. Regression methods are used to investigate whether the presence of specific disease combinations increases or decreases primary care costs compared with the cost of treating separate patients with each condition.

\section{METHOD}

Data

An initial random sample of 99997 patients stratified by age, sex, and practice was used, from the General Practice Research Database (GPRD), which contains around 5 million active primary care patients in the UK and is considered broadly representative of the general population. ${ }^{10}$ Patients in the initial sample were aged $\geq 18$ years and registered on 1 April 2005 at one of 182 'research standard' general practices. Eight practices were excluded because of missing data on deprivation status. This analysis is based on patients who were still alive and registered on 1 April 2007, giving us a final sample of 86100 patients aged 20 years and over from 174 practices.
Address for correspondence

Sandra Hollinghurst, Centre for Academic Primary Care, School of Social and Community Medicine, University of Bristol, Canynge Hall, Whatley Road, Bristol, BS8 2PS, UK.

E-mail: s.p.hollinghurstabristol.ac.uk

Submitted: 6 September 2012; Editor's response: 29 October 2012; final acceptance: 1 January 2013 This is the full-length article (published online 25 Mar 2013) of an abridged version published in print. Cite this article as: $\mathbf{B r} \mathbf{J}$ Gen Pract 2013; DOI: 10.3399/bjgp13X665242 


\section{How this fits in}

The prevalence of patients with more than one chronic condition is increasing in most developed countries and this is likely to continue as populations age. The burden of care for these patients is largely in primary care, however, the effect on primary care resource use over and above that due to ageing is unclear. Patients with comorbidities involving depression cost more than separate patients with the individual conditions, perhaps because of the complex nature of the conditions. Hypertension is cost-limiting when co-occurring with most diseases, probably because of treatment overlaps. Dementia is cost-limiting in combination with most other conditions; further work is needed to establish whether this reflects inadequate care. These results can inform management of chronic conditions in primary care to improve patient experience and the efficient and equitable allocation and use of resources.

\section{Primary care costs}

The cost per patient of primary care resource use during the year 1 April 2007 to 31 March 2008 was estimated. This included all consultations, prescribed medication, and tests initiated within the general practice. All resources were valued in pounds sterling ( $E$ ) at 2007/2008 prices.

Consultations included all face-to-face and telephone contacts, clinic visits, and out-of-hours encounters. The unit cost of each consultation was based on the type of consultation and staff member leading the consultation. An additional cost was attached to cover administrative activities such as the recording of results or sending mail to a patient when this was performed by a receptionist, administrator, or secretary. Unit costs were taken from Curtis ${ }^{11}$ and a study of GP earnings and expenses. ${ }^{12}$

Unit costs for prescribed drugs were based on standardised unit cost information provided by the GPRD. This combines data from several sources, including the National Drug Tariff ${ }^{13}$ for information on generic products, and branded product information sourced from the manufacturer. Each item observed in the patient level data was costed using drug name, strength and formulation. When there were multiple unit costs for a single prescription drug the median unit cost was used.

Tests and investigations were assigned to one of three categories: those performed within a standard surgery consultation; those involving laboratory testing; and those requiring the patient to attend a hospital.
Surgery-based tests were costed according to the consumables used, such as urine dipsticks; unit costs for laboratory tests were based on the pathology discipline: $;^{14}$ and for hospital-based tests and investigations requested through the general practice, such as X-rays, the study matched directly to entries in the NHS Reference Costs. ${ }^{14}$

\section{Identifying comorbidity}

Patients were identified if they had a current diagnosis on 1 April 2007 of one or more of 17 conditions incentivised within the Quality and Outcomes Framework (QOF) and which had previously been identified as being chronic. ${ }^{15}$ The conditions were asthma, atrial fibrillation, cancer, coronary heart disease (CHD), chronic kidney disease (CKD), chronic obstructive pulmonary disease (COPD), dementia, depression, diabetes, epilepsy, heart failure, hypertension, learning difficulties, mental health, obesity, stroke, and hypothyroidism. Version 16 of the QOF Implementation Business Rules was used, ${ }^{16}$ which provides the Read codes and additional criteria required to diagnose an individual with a given condition.

\section{Statistical analysis}

Multiple regression models were used to relate total primary care cost per patient to: 10-year age-sex band; deprivation using deciles of the Index of Multiple Deprivation (IMD) 2007:17 practice fixed effects; and the 17 chronic conditions including all main effects and two-way interactions between the conditions. The study's interest in mean costs and the large sample size determined ordinary least squares (OLS) regression to be most suitable despite the skewness of the cost data. ${ }^{18}$ As the prevalence and cost implications of comorbidity differ by age three separate models for three separate age groups were estimated: 20-39 years, 40-59 years, and $\geq 60$ years. All 136 $l=17 \times 16 / 2)$ two-way interaction terms in the model were included to test whether the change in cost due to the presence of a chronic condition depends on whether any other conditions are present. The estimated coefficient on each comorbidity interaction term is the difference in cost between treating an individual with both of those two specific conditions and the cost if each condition were to appear separately in two otherwise similar individuals.

The models were used to predict the mean annual cost of treating a patient with each possible combination of two conditions. The predicted costs for each age group were calculated at the mean values of age, sex, and deprivation, using the 
Table 1. Frequency, prevalence and cost, by condition

\begin{tabular}{|c|c|c|c|c|c|c|c|c|}
\hline \multirow[b]{2}{*}{ Condition } & \multirow[b]{2}{*}{$\begin{array}{c}\text { Sample } \\
\text { frequency }\end{array}$} & \multirow[b]{2}{*}{$\begin{array}{c}\text { Sample } \\
\text { prevalence, } \%\end{array}$} & \multirow{2}{*}{$\begin{array}{c}\text { England } \\
\text { prevalence } \\
2007 / 2008, \%\end{array}$} & \multirow{2}{*}{$\begin{array}{l}\text { Patients with only } \\
\text { this condition (out of } \\
\text { individuals with } \\
\text { this condition), \% }\end{array}$} & \multicolumn{4}{|c|}{$\begin{array}{l}\text { Annual mean and (SD) cost, } \mathrm{E} \text {, per } \\
\text { patient for individuals with only this condition }\end{array}$} \\
\hline & & & & & Total & Consultations & $\begin{array}{l}\text { Prescribed } \\
\text { medication }\end{array}$ & $\begin{array}{c}\text { Tests and } \\
\text { investigations }\end{array}$ \\
\hline Asthma & 5616 & 6.5 & $5.7^{c}$ & 43.6 & $358(521)$ & $116(12)$ & $219(447)$ & $23(62)$ \\
\hline Atrial fibrillation & 1818 & 2.1 & $1.31^{a}$ & 11.0 & 509 (602) & $190(165)$ & $267(521)$ & 53 (89) \\
\hline Cancer & 1414 & 1.6 & $1.11^{\mathrm{a}}$ & 31.5 & 596 (711) & $156(163)$ & $373(612)$ & 66 (130) \\
\hline $\mathrm{CHD}$ & 4849 & 5.6 & $3.51^{\mathrm{a}}$ & 16.1 & 581 (791) & $153(147)$ & 387 (713) & $41(80)$ \\
\hline CKD & 3302 & 3.8 & $3.7^{\mathrm{d}}$ & 6.9 & 604 (1714) & $195(170)$ & $364(1655)$ & $45(75)$ \\
\hline COPD & 1795 & 2.1 & $1.51^{\mathrm{a}}$ & 17.4 & 870 (764) & $198(200)$ & 626 (622) & $45(102)$ \\
\hline Dementia & 415 & 0.5 & $0.41^{a}$ & 18.3 & $714(639)$ & $168(164)$ & $522(556)$ & $24(77)$ \\
\hline Depression & 12811 & 14.9 & $10.9^{e}$ & 54.9 & $262(418)$ & $123(141)$ & $114(328)$ & 25 (68) \\
\hline Diabetes & 4336 & 5.0 & $4.8^{f}$ & 12.9 & $681(708)$ & $170(123)$ & 471 (671) & 40 (75) \\
\hline Epilepsy & 799 & 0.9 & $0.82^{c}$ & 38.7 & $674(749)$ & $140(160)$ & $502(684)$ & $32(85)$ \\
\hline Heart failure & 990 & 1.1 & $0.81^{a}$ & 3.5 & 781 (1262) & 215 (215) & 532 (1249) & $33(53)$ \\
\hline Hypertension & 15646 & 18.2 & $12.81^{a}$ & 32.0 & $416(417)$ & $140(123)$ & 244 (343) & $32(74)$ \\
\hline Learning difficulties & 319 & 0.4 & $0.32^{c}$ & 41.7 & 297 (474) & $87(97)$ & 199 (439) & $10(28)$ \\
\hline Mental health & 787 & 0.9 & $0.71^{\mathrm{a}}$ & 27.2 & $587(716)$ & $131(139)$ & $442(692)$ & $15(43)$ \\
\hline Obesity & 8543 & 9.9 & $9.4^{9}$ & 27.9 & 216 (315) & $105(115)$ & $87(224)$ & $23(61)$ \\
\hline Stroke & 2086 & 2.4 & $1.61^{\mathrm{a}}$ & 10.8 & $449(660)$ & $143(143)$ & $277(606)$ & $29(51)$ \\
\hline Hypothyroidism & 3364 & 3.9 & $2.71^{a}$ & 28.9 & 341 (374) & $142(118)$ & 160 (292) & 39 (76) \\
\hline None of the included conditions & 47400 & 55.1 & - & - & 131 (302) & $64(93)$ & $50(244)$ & $17(58)$ \\
\hline \multicolumn{9}{|c|}{$\begin{array}{l}\text { a Sample size: } 86100 \text { adults aged } \geq 20 \text { years. }{ }^{b} \text { England prevalence figures were obtained from publicly available national statistics reported as part of the national QOF. }{ }^{c} \text { England } \\
\text { prevalence based on all ages. }{ }^{d} \text { England prevalence based on ages } \geq 18 \text { years. }{ }^{\circ} \text { England prevalence based on ages } \geq 18 \text { years. This 2009/2010 figure was obtained from the }\end{array}$} \\
\hline
\end{tabular}

average practice fixed effect, and assuming the individual had no other conditions. The estimated coefficients for the two-way interaction effects from the OLS regression models indicate the effect of comorbidity on cost; positive values represent 'costincreasing' comorbidities (where the cost of treating both conditions in one patient is higher than two patients each with one condition) and negative values indicate 'cost-limiting' comorbidities /where the cost of a patient with two conditions is less than two patients each with one of the conditions). Coefficients are reported for comorbidities with at least 30 individuals in the sample and a $P$-value $<0.1$. Estimates of prevalence-adjusted costs were obtained by combining the patient-level comorbidity cost effects with the prevalence of each comorbid combination to illustrate the impact of each comorbid combination on cost at a population level. STATA (version 11.2) was used for the statistical analysis.

\section{RESULTS}

Patient characteristics, prevalence, and costs of chronic conditions

Patients in the sample were evenly distributed in terms of sex (males 49\%; females 51\%), age category (20-29 years, $30 \%$; 40-59 years, 37\%; $\geq 60$ years, 33\%) and deprivation. Hypertension was the most common QOF condition (18\%) followed by depression (15\%) and this was true of both males and females. The most common four comorbidities also included hypertension, in conjunction with obesity, coronary heart disease, diabetes, and chronic kidney disease.

Table 1 shows the sample frequency and prevalence of each condition and the average cost for a patient with only that condition. Prevalence for England ${ }^{19}$ is given for comparison; for all conditions, the prevalence in the study sample is higher than the national prevalence.

Forty-five per cent $(n=38700)$ of patients in the sample had at least one chronic condition and $20 \%(n=17340)$ had at least two. The mean annual cost of caring for patients who have only one condition ranges from $€ 216$ (SD $€ 315$ ) for obesity to €870 (SD €764) for COPD. In general, medication accounts for a higher proportion of cost in patients with the more costly conditions; consultations account 
Figure 1. Estimated additional annual cost, $\mathcal{E}$, of treating a

patient with comorbidity compared with two patients each

with only one of the conditions. $C H D=$ coronary heart disease.

$C K D=$ chronic kidney disease. $C O P D=$ chronic obstructive

pulmonary disease.
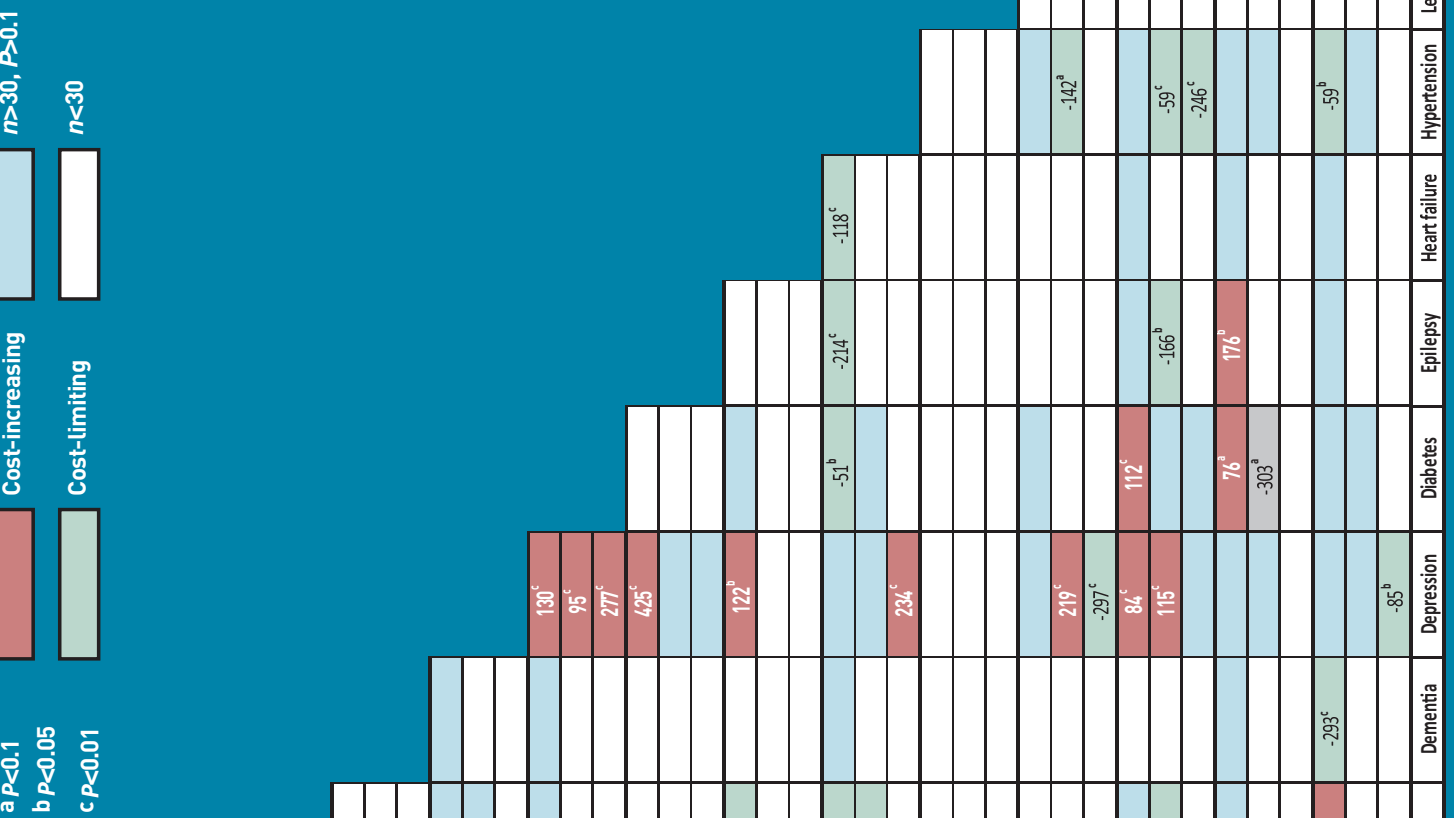

을 충

$\approx$

范

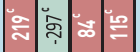

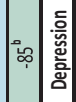

翣量

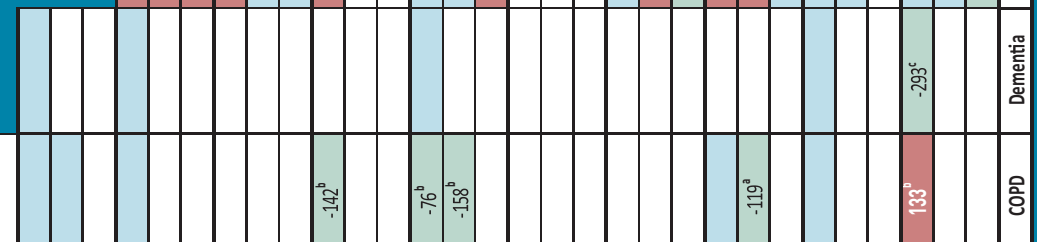

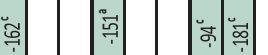

:़े

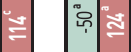

疍

:

ำ

$\stackrel{\infty}{\sim}$

$\underset{\substack{\infty \\ \hdashline}}{0}$

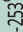

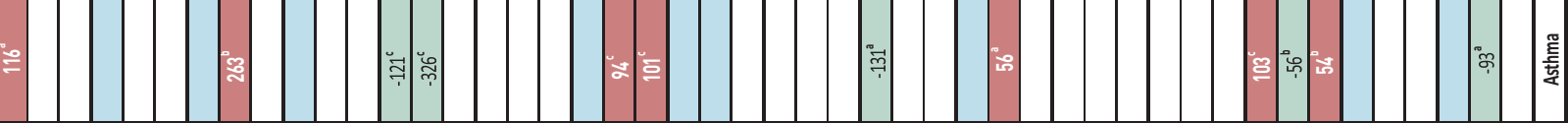

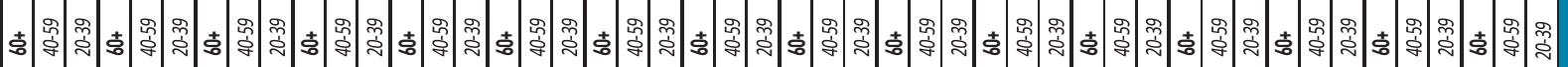

\begin{tabular}{|c|c|c|c|c|c|c|c|c|c|c|c|c|c|c|}
\hline 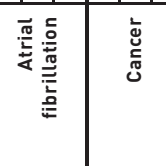 & 옹 & 웜 & a & 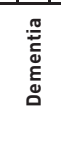 & 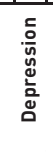 & 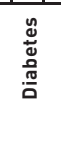 & $\begin{array}{l}\frac{\bar{a}}{2} \\
\frac{\vec{\omega}}{4}\end{array}$ & 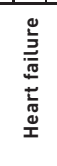 & 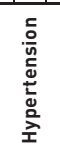 & 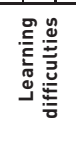 & 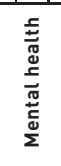 & $\begin{array}{l}\frac{z}{\bar{D}} \\
\text { 总 }\end{array}$ & 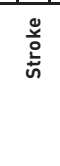 & \\
\hline
\end{tabular}


Table 2. Estimated prevalence-adjusted cost effect ${ }^{\text {a }}$ of comorbidity compared with separate patients with each disease

\begin{tabular}{lc}
\multicolumn{2}{c}{ Age 20-39 years } \\
\hline & $\begin{array}{c}\text { Estimated } \\
\text { prevalence-adjusted } \\
\text { cost, } \mathbf{\epsilon} \text {, and (90\% CI) } \\
\text { per 1000 patients }\end{array}$ \\
Comorbidity & $1257(841$ to 1672$)$ \\
\hline Asthma/Depression & $603(420$ to 786$)$ \\
Depression/Diabetes & $538(364$ to 711$)$ \\
Depression/Hypertension & $419(95$ to 743$)$ \\
Asthma/Obesity & $268(64$ to 472$)$ \\
Obesity/Thyroid &
\end{tabular}

Depression/Mental health $-1040(-1306$ to -774$)$ Hypertension/Obesity $\quad-940(-1194$ to -685$)$ Depression/Thyroid $\quad-280(-514$ to -47$)$

\begin{tabular}{cc}
\multicolumn{2}{c}{ Age 40-59 years } \\
\hline Comorbidity & $\begin{array}{c}\text { Estimated } \\
\text { prevalence-adjusted } \\
\text { cost, } \mathbf{E} \text {, and (90\% CI) } \\
\text { per 1000 patients }\end{array}$ \\
\hline Depression/Obesity & 2817 (1993 to 3641$)$ \\
Asthma/Depression & 1542 (902 to 2182$)$ \\
Depression/Mental health & 1007 (621 to 1394$)$ \\
Mental health/Obesity & $838(604$ to 1073$)$ \\
Depression/Diabetes & $691(262$ to 1120$)$ \\
CHD/Obesity & $605(160$ to 1050$)$ \\
Asthma/Hypertension & $603(95$ to 1110$)$ \\
CHD/Depression & $569(225$ to 912$)$ \\
Asthma/CHD & $558(339$ to 766$)$ \\
CHD/Diabetes & $433(135$ to 731$)$ \\
Cancer/Depression & $269(74$ to 464$)$ \\
\hline Hypertension/Obesity & $-2020(-3127$ to -913$)$ \\
Asthma/COPD & $-1018(-1312$ to -723$)$ \\
Asthma/Obesity & $-685(-1245$ to -124$)$ \\
CHD/Hypertension & $-626(-1134$ to -119$)$ \\
CKD/Obesity & $-575(-849$ to -302$)$ \\
Diabetes/Stroke & $-365(-549$ to -180$)$ \\
CKD/Depression & $-358(-580$ to -136$)$ \\
COPD/Hypertension & $-294(-501$ to -86$)$ \\
Asthma/Thyroid & $-256(-486$ to -27$)$ \\
CHD/Thyroid & $-231(-375$ to -88$)$ \\
Epilepsy/Obesity & $-226(-403$ to -50$)$ \\
COPD/Obesity & $-199(-394$ to -3$)$ \\
Hypertension/Mental health & $-171(-337$ to -5$)$ \\
&
\end{tabular}

\begin{tabular}{|c|c|}
\hline \multicolumn{2}{|c|}{ Age $\geq 60$ years } \\
\hline Comorbidity & $\begin{array}{c}\text { Estimated } \\
\text { prevalence-adjusted } \\
\text { cost, } \mathrm{E} \text {, and }(90 \% \mathrm{CI}) \\
\text { per } 1000 \text { patients }\end{array}$ \\
\hline Diabetes/Obesity & 4887 (3013 to 6762) \\
\hline Depression/Diabetes & 2133 (1196 to 3071) \\
\hline Depression/Obesity & 1936 (791 to 3080 ) \\
\hline Asthma/Obesity & 1436 (574 to 2297) \\
\hline Diabetes/Stroke & 902 (106 to 1697) \\
\hline Depression/Epilepsy & 834 (530 to 1139) \\
\hline Depression/Heart failure & $672(143$ to 1201$)$ \\
\hline Cancer/CKD & 606 (56 to 1155 ) \\
\hline COPD/Thyroid & 564 (134 to 993) \\
\hline Asthma/Atrialfib & 534 (81 to 988 ) \\
\hline Epilepsy/Stroke & 491 (81 to 902) \\
\hline CHD/Hypertension & $-9497(-12460$ to -6533$)$ \\
\hline CKD/Hypertension & $-7455(-10726$ to -4185$)$ \\
\hline Diabetes/Hypertension & $-3688(-6709$ to -667$)$ \\
\hline Atrialfib/Heart failure & $-3106(-4015$ to -2197$)$ \\
\hline Heart failure/Hypertension & n -2341 (-3754 to -928$)$ \\
\hline Hypertension/Thyroid & $-2164(-3884$ to -443$)$ \\
\hline $\mathrm{CHD} / \mathrm{CKD}$ & $-2105(-3591$ to -618$)$ \\
\hline COPD/Hypertension & $-1853(-3209$ to -496$)$ \\
\hline Asthma/COPD & $-1792(-2722$ to -862$)$ \\
\hline CKD/Depression & $-1489(-2389$ to -588$)$ \\
\hline CHD/Diabetes & $-1408(-2743$ to -74$)$ \\
\hline CKD/COPD & $-1391(-2056$ to -727$)$ \\
\hline CKD/Thyroid & $-1375(-2260$ to -490$)$ \\
\hline Atrialfib/CKD & $-1153(-2065$ to -240$)$ \\
\hline CKD/Heart failure & $-1150(-2019$ to -280$)$ \\
\hline Atrialfib/Thyroid & $-1018(-1594$ to -441$)$ \\
\hline Obesity/Stroke & $-952(-1634$ to -270$)$ \\
\hline CKD/Stroke & $-927(-1834$ to -21$)$ \\
\hline Atrialfib/Stroke & $-885(-1650$ to -120$)$ \\
\hline Obesity/Thyroid & $-850(-1657$ to -44$)$ \\
\hline Epilepsy/Hypertension & $-846(-1378$ to -314$)$ \\
\hline Cancer/COPD & $-828(-1154$ to -501$)$ \\
\hline COPD/Heart failure & $-785(-1344$ to -227$)$ \\
\hline Atrialfib/COPD & $-682(-1176$ to -187$)$ \\
\hline Cancer/Thyroid & $-569(-914$ to -225$)$ \\
\hline Dementia/Thyroid & $-544(-823$ to -266$)$ \\
\hline Asthma/Heart failure & $-475(-900$ to -50$)$ \\
\hline Cancer/Heart failure & $-349(-635$ to -63$)$ \\
\hline CKD/Dementia & $-339(-655$ to -23$)$ \\
\hline
\end{tabular}

The cost effect is calculated as the estimated coefficient on the two-way interaction term in the ordinary least squares regression, multiplied by the age specific prevalence of the comorbidity, multiplied by 1000. It represents the estimated cost effect per 1000 general practice patients. Effects shown only for comorbidities with at least 30 individuals in the estimation sample and where the coefficient on the two-way interaction term had $\mathrm{P}<0$. 1. Atrialfib = atrial fibrillation. $C H D=$ coronary heart disease. $C K D=$ chronic kidney disease. $C O P D=$ chronic obstructive pulmonary disease. Thyroid $=$ hypothyroidism. for the highest proportion in depression and obesity.

Patient-level and prevalence-adjusted cost implications of specific comorbidities Figure 1 shows the disease combinations where the cost of treating a single patient with two conditions is significantly different $(P<0.1)$ from the cost of treating two patients each with just one of the conditions.
All conditions are found to be both cost-increasing and cost-limiting when combined with other conditions, with the exception of dementia, which is not costincreasing when co-occurring with any other chronic condition. The proportion of comorbidities that are cost-limiting rather than cost-increasing is greater in the older age groups. Depression, in combination with a wide range of other conditions, in 
particular diabetes, is cost-increasing across all three age cohorts in most instances. CKD, COPD and hypertension in combination with each other and with other conditions are the most common costlimiting morbidities, particularly in patients aged $\geq 60$ years, where these conditions are most likely to occur.

Table 2 provides estimates of the cost implications, at a population level, of the important comorbidities identified above Iwhere $P$-value is $<0.1$ and there are at least 30 patients) when prevalence is taken into account. This indicates the importance of each comorbidity from a budgetary management perspective. Across all age groups the largest comorbidity effect is in the various combinations of depression, obesity, diabetes, and/or asthma. The largest cost-limiting effects are seen in the over 60s age group. Here, hypertension in combination with a number of other conditions Iprincipally CHD, CKD, and diabetes) is the most common cost-limiting condition.

\section{DISCUSSION}

\section{Summary}

Depression is the most important contributor to the cost implications of comorbidity across all ages. This is at the level of the individual patient and when prevalence is taken into account. Comorbidities are more likely to be costlimiting in older patients than in those aged $<60$ years. Hypertension is cost-limiting, particularly when co-occurring with other cardiovascular conditions, at individual patient level and when prevalence is taken into account.

\section{Strengths and limitations}

This study used data from a large, reliable, and representative primary care database of English practices. Prevalence rates in the study sample were similar to those quoted for England, ${ }^{19}$ allowing for the fact that the national prevalence for most conditions is based on the whole population whereas the study data included only adults. Furthermore, there have been no major changes in primary care practice in the past few years that are likely to have influenced these results so these findings should be generalisable to the wider general practice population in the UK.20,21 Although the sample size was reasonably large the low prevalence of some comorbidities meant that some interaction effects could not be reliably estimated. It was a conservative choice not to report comorbidity effects that were estimated using fewer than 30 individuals.
A pragmatically defined set of 17 chronic diseases was used. The advantage of using diseases included in the QOF is that these are likely to have been reliably and consistently coded in all practices. However, the QOF diseases were originally selected as conditions where the quality of care could be measured and improved, rather than to represent the spectrum of chronic diseases. There are conditions missing from this list that are common and cause significant morbidity, for example, osteoarthritis.

No formal correction for multiple testing was used in the analysis, as controlling the overall type I error rate would have decreased statistical power (the ability to identify comorbidity effects where they truly are important). Therefore, it must be acknowledged that several comorbidity effects would be expected to be included in Figure 1 and Table 2 simply due to chance. For example, in the oldest age group there are 99 comorbidities with at least 30 individuals and therefore, assuming no effect of comorbidity on costs, 10 (=99x0.1) significant comorbidity effects would be expected simply due to chance. However, 40 significant comorbidity effects were found in this age group. This analysis focuses on two-way disease interactions; higher-order interactions, arising when patients have more than two chronic conditions, were excluded from the regression model due to the small numbers of individuals with each combination. In the dataset $9 \%$ of patients had three or more of the conditions and these were spread across the many (680 for three-way comorbidities) possible combinations. Omitting higher order interactions will bias the estimates of the cost implications of comorbidity only if only if higher order interactions have a sizeable effect on cost over and above the main effects and two way interactions.

Some comorbidities were found to be costincreasing and cost-limiting depending on the age-band. Such examples are: asthma/ obesity, which is cost-increasing in older and young people but cost-limiting in 40-59 year olds; and diabetes/stroke which is also costincreasing in older people but cost-limiting in the 40-59 year olds. There is no clear explanation for this; it could be speculated that younger people who have a stroke (as classified by QOF) are more likely to have a mild event or TIA, resulting in fewer complications, but it is equally likely that these findings are by chance. In this exploratory analysis, involving a large number of tests, there is a high chance of obtaining some false positive results so in drawing conclusions the focus is on those findings that are consistent. 


\section{Comparison with existing literature}

There are no studies that have estimated the implications of such a wide range of comorbidities for total primary care costs. However, the results of this study are compatible with the findings of studies that have investigated specific combinations of diseases. Studies looking at the impact of comorbid mental health problems on the use of healthcare resources by patients with diabetes have found that in general primary care and secondary care costs increase in the presence of comorbid mental health problems. ${ }^{22,23,24}$ The combination of diabetes and depression was found to be greatly cost-increasing; diabetes and mental health was cost-limiting in the study sample, however, mental health as defined under the QOF relates to more severe conditions (for example schizophrenia and long-term psychosis) rather than common mental health problems such as depression. Nichols and Brown ${ }^{9}$ found patients with both diabetes and cardiovascular disease had higher total costs than the sum of costs for patients with only cardiovascular disease or only diabetes. This study found that diabetes and CHD was only cost-increasing in the middle-aged patient, although the data relate specifically to primary care costs.

\section{Implications for practice and research}

One interpretation of the results is that there are three categories of disease combinations, those that are: costincreasing, mainly due to a combination of depression with a physical comorbidity; cost-limiting because treatment for the two conditions overlaps; cost-limiting for no apparent reason but possibly indicating that care for some patients with comorbidity is not as extensive as for those without complex needs. This classification provides information that could be useful to clinicians and managers, and which could benefit patients.

Where comorbidities are cost-increasing, there may be merit in considering the appropriateness of multidisease management or pathways. ${ }^{25}$ Although the current QOF guidelines require ongoing monitoring of patients with several common chronic conditions, the study analysis suggests that more efficient management might be possible. This is particularly true of conditions where the cost of consultations rather than medication represents an important proportion of the total, for example, depression and obesity, where practitioner support is crucial. The findings of this study highlight, as has previous research, that depression in patients with comorbid physical conditions increases the burden of illness for individuals and also has a major impact on costs at a population level because depression is so common. There is scope for the development of novel care pathways for patients with a chronic physical condition and depression. As the NICE guidance on the management of depression and physical illness notes, ${ }^{26}$ there is an association between depression and increased use of healthcare resources, so improved care is likely to improve patient experience and health outcomes and reduce demands on primary care resources. Although collaborative care is advocated by NICE there appears to be little evidence of widespread adoption ${ }^{27}$ and few examples of exemplary practice. There is ample scope for developing interventions and techniques that would enable patients to be treated holistically. This would recognise the equal importance of physical and mental conditions and the way they interact, and could involve regular drug review and strategies to help patients adjust to living with a long-term condition.

The results of this study suggest that there are a number of conditions, for example CHD, CKD, COPD, diabetes, and heart failure, which in combination with hypertension are cost-limiting. This may have implications for clinical guidelines and for pay-for-performance schemes, both to avoid inappropriate incentives ${ }^{28}$ and paying twice for aspects of treatment that overlap across conditions.

If there are no obvious clinical grounds to explain why the needs of a patient with one condition should change in the presence of a second condition, but utilisation is shown to be lower, this may be evidence for unmet need, which has importance for policy but which is often hard to identify or measure. The finding that comorbidities involving dementia are generally cost-limiting suggests that patients with dementia may be one group who have unmet needs.

This study raises important questions that would merit further research. First, with the focus on primary care costs useful information can be gained about resource allocation and budgetary management in primary care. A more powerful model would also include secondary care costs and if linked patient-level data on primary and secondary care healthcare use were available, more reliable estimates could be used to inform this process. Developing systems that capture these data should be a priority.

Second, the results invite exploration of the cost-limiting comorbidities where care 
of patients with comorbidity is less extensive than for patients with a single condition. In particular, further investigation is needed to explain the finding that patients with dementia appear to use fewer resources to treat some comorbid conditions than those without dementia. There is some evidence supporting the view that patients in care homes may receive poorer care than those in the community ${ }^{29}$ and previous work focusing on the care of dementia patients in North America has observed under-reporting of other conditions, notably depression and pain, ${ }^{30}$ which may also point to under-management of comorbidities. However, this finding may also be accounted for by GPs making the judgement that intensive treatment of some comorbidities in dementia patients is inappropriate. The evidence base here is weak, suggesting an urgent need to establish the extent to which comorbidities are recognised and managed in dementia patients in the UK.

This study describes costs associated with comorbidity in primary care patients; there has been no attempt to relate this to quality of care. An important unanswered question is how the findings might be linked to patient outcomes; such an analysis would be a useful addition to the debate and could shed further light on the interpretation of these results. Comorbidity can have either a positive or negative impact on the cost of managing patients in primary care. This can highlight opportunities for more efficient management, have implications for clinical guidelines, pay-for-performance schemes, and also highlight priorities for improved care, particularly for patients with depression or dementia. 


\section{REFERENCES}

1. Valderas JM, Starfield B, Sibbald B, et al. Defining comorbidity: implications for understanding health and health services. Ann Fam Med 2009; 7(4): 357-363.

2. Starfield B. Threads and yarns: weaving the tapestry of comorbidity. Ann Fam Med 2006; 4(2): 101-103.

3. Charlson M, Charlson RE, Briggs W, Hollenberg J. Can disease management target patients most likely to generate high costs? The impact of comorbidity. $J$ Gen Intern Med 2007; 22(4): 464-469.

4. Lehnert T, Heider D, Leicht $H$, et al. Review: health care utilization and costs of elderly persons with multiple chronic conditions. Med Care Res Rev 2011; 68(4): 387-420.

5. Glynn LG, Valderas JM, Healy P, et al. The prevalence of multimorbidity in primary care and its effect on health care utilization and cost. Fam Pract 2011; 28(5): 516-523.

6. Brilleman SL, Gravelle H, Hollinghurst S, et al. Keep it simple? Predicting primary health care costs with measures of morbidity and multimorbidity. CHE Research Paper, 72. York: University of York, 2011. http://www.york. ac.uk/che/publications/in-house (accessed 20 Feb 2013).

7. Finkelstein EA, Bray JW, Chen $\mathrm{H}$, et al. Prevalence and costs of major depression among elderly claimants with diabetes. Diabetes Care 2003; 26(2): 415-420.

8. Johansson PA, Farup PG, Bracco A, Vandvik PO. How does comorbidity affect cost of health care in patients with irritable bowel syndrome? A cohort study in general practice. BMC Gastroenterol 2010; 10: 31

9. Nichols G, Brown J. The impact of cardiovascular disease on medical care costs in subjects with and without type 2 diabetes. Diabetes Care 2002; 25(3): 482-486.

10. Lawrenson R, Williams T, Farmer R. Clinical information for research; the use of general practice databases. J Public Health Med 2009; 21(3): 299-304.

11. Curtis L. Unit costs of health and social care 2009. Kent, UK: PSSRU, University of Kent, 2010.

12. NHS Information Centre. Technical Steering Committee GP earnings and expenses 2007/08. Date.Gov.uk, 2010. http://data.gov.uk/dataset/gp_earnings_ and_expenses (accessed 20 Feb 2013).

13. National Health Service. NHS drug tariff. http://uww.nhsbsa.nhs.uk/ PrescriptionServices/924.aspx (accessed 20 Feb 2013).

14. Department of Health. NHS reference costs 2007/08. London: DoH, 2009. http://www.dh.gov.uk/en/Publicationsandstatistics/Publications/ PublicationsPolicyAndGuidance/DH_098945 laccessed 20 Feb 2013).

15. Salisbury C, Johnson L, Purdy S, et al. Epidemiology and impact of multimorbidity in primary care: a retrospective cohort study. Br J Gen Pract 2011; DOI: 10.3399/bjgp11X548929.

16. NHS Primary Care Commissioning. QOF Implementation Business Rules v16. http://www.pcc-cic.org.uk/article/qof-business-rules-v220 laccessed $11 \mathrm{Mar}$ 2013).

17. Department for Communities and Local Government. The English Indices of Deprivation 2007. Torbay: Torbay Council, 2008.

18. Lumley $T$, Diehr P, Emerson $S$, Chen $L$. The importance of normality assumption in large public health data sets. Annu Rev Public Health 2002; 23: 151-169.

19. NHS Information Centre. National Quality and Outcomes Framework Statistics for England 2007/08. http://www.nepho.org.uk/securefiles/130311_1412// QOF\%20REPORT.pdf (accessed 11 Mar 2013).

20. Clinical Practice Research Datalink. Recording guidelines for vision users. London: CPRD. http://www.gprd.com/_docs/recordingguidelines.pdf laccessed 20 Feb 2013).

21. Khan NF, Harrison SE, Rose PW. Validity of diagnostic coding within the General Practice Research Database: a systematic review. Br J Gen Pract 2010; DOI: 10.3399/bjgp10X483562.

22. Hutter N, Schnurr A, Baumeister H. Healthcare costs in patients with diabetes mellitus and comorbid mental disorders-a systematic review. Diabetologia 2010; 53(12): 2470-2479.

23. Naylor C, Parsonages M, McDaid D, et al. Long-term conditions and mental health: the cost of co-morbidities. London: The King's Fund and Centre for Mental Health, 2012.

24. Das-Munshi J, Stewart R, Ismail K, et al. Diabetes, common mental disorders, and disability: Findings from the UK National Psychiatric Morbidity Survey. Psychosom Med 2007; 69(6): 543-550.

25. Barnett K, Mercer SW, Norbury M, et al. Epidemiology of multimorbidity and implications for health care, research, and medical education: a cross-sectional study. Lancet 2012; 30(9836): 37-43.

26. National Institute for Health and Clinical Excellence. Depression in adults with a chronic physical health problem. Treatment and management. Clinical guideline 91. London: NICE, 2009.

27. Mercer SW, Gunn J, Bower P, et al. Managing patients with mental and physical multimorbidity. BMJ 2012; 345: e5559.

28. Boyd CM, Darer J, Boult C, et al. Clinical practice guidelines and quality of care for older patients with multiple comorbid diseases: implications for pay for performance. JAMA 2005; 294(6): 716-724.

29. Barnett K, McCowan C, Evans JM, et al. Prevalence and outcomes of use of potentially inappropriate medicines in older people: cohort study stratified by residence in nursing home or in the community. BMJ Qual Saf 2011; 20(3): 275-281

30. Maslow K, Heck E. Dementia care and quality of life in assisted living and nursing homes: perspectives of the Alzheimer's Association. Gerontologist 2005; 45 Spec No 1(1): 8-10. 